\title{
Mucin-Depleted Foci of the Mouse Intestinal Tract
}

National Cancer Institute

\section{Source}

National Cancer Institute. Mucin-Depleted Foci of the Mouse Intestinal Tract. NCI

Thesaurus. Code C107671.

Precancerous dysplastic lesions depleted of mucin in the colonic mucosa of the mouse. 